\title{
The Female Sexual Function Index: Transculturally Adaptation and Psychometric Validation in Spanish Women
}

\author{
Beatriz Sánchez-Sánchez ${ }^{\circledR}$, Beatriz Navarro-Brazález® ${ }^{\circledR}$, Beatriz Arranz-Martín, \\ Óscar Sánchez-Méndez ${ }^{\circledR}$, Irene de la Rosa-Díaz * and María Torres-Lacomba $\mathbb{}$ \\ Physiotherapy in Women's Health (FPSM) Research Group, Physiotherapy Department, Faculty of Medicine \\ and Health Sciences, University of Alcalá, Alcalá de Henares, 28805 Madrid, Spain; \\ beatriz.sanchez@uah.es (B.S.-S.); b.navarro@uah.es (B.N.-B.); beatriz.arranz@edu.uah.es (B.A.-M.); \\ osmfisio@gmail.com (Ó.S.-M.); maria.torres@uah.es (M.T.-L.) \\ * Correspondence: fisioterapia.mujer@uah.es
}

Received: 31 December 2019; Accepted: 2 February 2020; Published: 5 February 2020 updates

\begin{abstract}
Background: The evaluation of sexual function is an important outcome in women who suffer some pelvic floor disorders (PFD). The Female Sexual Function Index (FSFI) is the most widely used questionnaire to evaluate the sexual health in female population. This study presents the adaptation and psychometric validation of the FSFI for Spanish women with PFD. Methods: The Spanish version of the FSFI was developed through the forward and backward translation process. The psychometric properties of reliability, validity, responsiveness, and feasibility were conducted in Spanish women with PFD who were assigned to the case or control group (with or without sexual dysfunction respectively). Results: A total of 323 Spanish women with PFD were recruited. The cross-cultural adaptation of the Spanish FSFI achieved a good semantic, conceptual, idiomatic, and content equivalence. The test-retest reliability was shown to be high in all of the cases. The convergent validity showed high results in the domain intercorrelations between each domain and total FSFI. The discriminant validity showed statistically significant differences between sexual dysfunction and control groups. The responsiveness was shown to be moderate to good in the dimensions and excellent in the total FSFI. Conclusions: Spanish FSFI can be used as a reliable, valid, responsive, and feasible instrument for assessing sexual function in women.
\end{abstract}

Keywords: FSFI; Spanish; pelvic floor disorders; sexual dysfunction; validity; reliability; responsiveness

\section{Introduction}

Sexual health is recognized by the World Health Organization as the complete well-being state related to sexuality, including physical, emotional, mental, and social welfare [1]. The compromise of sexual health supposes the development of sexual dysfunction, which affects nearly $40 \%-50 \%$ of women [2,3]. Different definitions of all forms of female sexual dysfunction (FSD) have been described. In 2015, the Fourth International Consultation on Sexual Medicine adopted the definitions of sexual dysfunction in women, consisting of: hypoactive sexual desire dysfunction, female sexual arousal dysfunction, female orgasmic dysfunction, female genital-pelvic pain dysfunction, persistent genital arousal disorder, postcoital syndrome, hypohedonic orgasm, and painful orgasm [4].

FSD has multifactorial causes, it is associated with a wide range of psychosocial and biomedical risk factors, like urogynaecological disorders or several metabolic diseases, such as diabetes mellitus, obesity, and metabolic syndrome [5]. Sexual dysfunction involves physical, social, and psychological 
dimensions, affecting women's quality of life [6]. It is a frequent problem among the women population, especially in urogynaecological patients [7]. In this way, different studies have found that sexual complaints are common among women with pelvic floor disorders (PFD), recognizing the urinary incontinence, overactive bladder, or pelvic organ prolapse as risks factors for sexual dysfunction [8-12]. Twenty-five percent to $50 \%$ of women who seek treatment for PFD report an impairment in sexual function [9].

Thus, the evaluation of sexual function in women is an important outcome in different medical specialties and it is recognized as an integral part of quality of life. This evaluation is important, especially in women who suffer some PFD, since PFD symptoms are associated with sexual dysfunction, reduced sexual arousal, infrequent orgasm, and dyspareunia [13]. It is necessary to perform not only the clinical assessment in order to quantify, classify, and design an adequate treatment for PFD, but also the patients' subjective perceptions. Some specific tools have been created to measure the subjective perception of quality of life and symptoms in women with PFD. The Pelvic Floor Distress Inventory short form and the Pelvic Floor Impact Questionnaire short form are psychometrically-validated and self-administered questionnaires that can address the presence and severity of PFD symptoms and their impact on quality of life [14]. The Pelvic Floor Distress Inventory short form and the Pelvic Floor Impact Questionnaire short form have been adapted and validated into Spanish language [15]. Although these questionnaires are recommended and widely used for PFD patients, it does not include questions regarding sexual function. Therefore, an assessment tool for female sexual function is necessary for PFD in women within the Spanish population. Nevertheless, the creation of new assessment tools is expensive and time consuming; for that, it is recommended to adapt and validate existing questionnaires in different populations where they will be administered. This way, the Female Sexual Function Index (FSFI) is the most widely used questionnaire for evaluating the sexual health in female population [16]. FSFI was developed by Rosen et al. in 2000, and it is a 19-item multidimensional self-reporting measure that quantified female sexual dysfunction in six domains: desire, arousal, lubrication, orgasm, satisfaction, and pain [17]. FSFI has been adapted and validated into more than 20 languages (e.g., [16,18-21]) and it is regarded as the de facto "gold standard" to assess the female sexual function [22]. Although there are two Spanish-Hispanic versions validated for Chilean and Colombian women [23,24], those versions could not be used in Spain, mainly because even if it is the same language, there are different expressions, contexts, and cultures and its use could imply an important penalization in the obtained data. Despite being a recommended international questionnaire, the Spanish version of FSFI in female Spanish sample has not been found. The aim of the present study has been adapting the original English FSFI into Spanish, and evaluating its psychometric properties of reliability, validity, responsiveness, and feasibility among Spanish women with PFD to considerate it as a reference instrument to assess female sexual function.

\section{Materials and Methods}

\subsection{Translation and Cultural Adaptation}

This study was a cross-sectional observational study that was conducted from March 2014 to February 2017. This study (OE21/2013) was approved by «BLINDED» Hospital's Clinical Research Ethics Committee in «BLINDED».

The study was divided into three phases pursuant to the International Society for Pharmacoeconomics and Outcomes Research (ISPOR) Task Force for Translation and Cultural Adaptation [25]. Two English-Spanish translators (native Spanish speakers) translated the original version of the FSFI, written in English, to create equivalent texts regarding semantics, concepts, idiomatic and contents. Both of the translators worked separately and obtained two versions in Spanish that proved to be equivalent to the original version. The translators proofread the translations and, together with the research team, agreed to the synthesis of the Spanish translation. 
Secondly, two professional Spanish-English translators (native English speakers) worked autonomously to get the back-translation, thus creating two English versions from the previous Spanish translation. Subsequently, an Expert Committee, considering both the back-translation and the Spanish-translated text, agreed to the Spanish version of the FSFI and to their equivalence to the original.

Thirdly, the Spanish preliminary version was given to 20 native Spanish-speaking women who fulfilled the inclusion criteria, for them to test its feasibility, equivalence, and comprehensibility. They filled in the questionnaire and were later interviewed in person so that any difficulties to understand the items could be identified and corrected. The FSFI's Spanish version was obtained after identifying and amending some minor details. The study reporting followed the "Strengthening the Reporting of Observational studies in Epidemiology" (STROBE) guidelines (Table S1 Supplementary Material).

\subsection{Participants and Procedure}

All women who were assessed by the «BLINDED» Research Group of the «BLINDED» and fulfilled the inclusion criteria were informed about the study and invited to participate. So, the written informed consent was obtained from all of the participants. The inclusion criteria were the following: female diagnosed with PFD, above 18 years of age, having been sexually active within the previous four weeks, being able to read and to understand Spanish language. The exclusion criteria were: current pregnancy or mental incapacity to fill in the questionnaire. The recruited women were provided with a brief study explanation by a researcher and diagnosed of FSD based on the Diagnostic and Statistical Manual of Mental Disorders, Fifth Edition (DSM-5) [26] that assessed the presence (or absence) of FSD, and that was administered during a face-to-face interview. In this way, with this diagnosis, the recruited women were assigned to the case group (with FSD) or to the control group (without FSD). The sample size has been based on the general recommendations of Terwee et al. [27], which recommend a subject-to-item ratio of at least 4:1, with a minimum of 100 subjects.

At baseline, women completed the Spanish versions of FSFI and a sociodemographic form. A subsample of 31 women filled in the FSFI again two-four weeks later in order to analyze the test-retest reliability. No treatment was delivered during this time; this interval was chosen to ensure that women's symptoms remained unchanged and long enough to ensure that they would not recall their baseline responses. A subgroup of women from the FSD group was evaluated again after the Physiotherapy treatment to evaluate responsiveness. The average time was recorded.

\subsection{Measures}

The tools used in this study included: participant characteristics' form, DSM-5, and the Spanish versions of FSFI.

\subsubsection{Participant Characteristics}

The women's baseline characteristics collected were: age, educational level, marital status, occupational status, annual family income, vaginal delivery, and menopause

\subsubsection{Diagnostic and Statistical Manual of Mental Disorders, Fifth Edition}

The DSM-5 is a widely psychiatric system used internationally for classifying the sexual dysfunction proposed by the American Psychiatric Association [26].

\subsubsection{Female Sexual Function Index}

The FSFI is a multidimensional self-report instrument that was developed by Rosen et al. to assessing female sexual function over the past 4 weeks [17]. It contains 19 items into six subscales: sexual desire (items 1 and 2), arousal (items 3, 4, 5 and 6), lubrication (items 7, 8, 9, and 10), orgasm (items 11, 12, and 13), satisfaction (items 14, 15 and 16), and pain (items 17, 18, and 19). The score range 
for items 3 to 14 and 17 to 19 between $0-5$; for items 1,2, 15, and 16 between $1-5$. The full-scale score range is from 2 to 36 , with the higher scores indicating better sexual function.

\subsection{Data Analysis}

The FSFI's Spanish version was tested for reliability, validity, responsiveness, and feasibility.

Statistical analysis of data that were obtained was conducted while using SPSS version 24.0. Statistical significance was assumed at $p<0.05$. COSMIN recommendations were used as a guide for evaluating the psychometric properties [28].

Reliability was assessed by the test-retest reliability and internal consistency. The test-retest reliability (the degree to which a measurement is free from error) [28] was measured by the intraclass correlation coefficient (ICC) for the total score and scores of each domain. Good values of test-retest reliability are considered greater than 0.7 [27]. A test-retest analysis of two-four weeks was used. Internal consistency (the degree of interrelatedness among each domain in the questionnaire and for all the items) was measured by means of Cronbach's alpha ( $\alpha$ ), considered a value of 0.7 good reliability, the higher the value, the greater the internal consistency [27,29].

Validity was assessed by the content and construct validity (factorial, convergent, and discriminant). Although content validity for assessing the ability of items to collect health status was guaranteed by the validation of the original scale, in this study, the Expert Committee's (consisting of a methodologist, three health professionals (one physical therapist, one physician, one gynecologist), one language professional, and two translators (forward and backward translators)) opinion was also taken into account to judge the ability of questionnaires to assess all dimensions, and the pilot study subjects opinion of 20 women, who reported completing the questionnaires.

Factorial validity, the degree to which each item relates to the hypothesized domain with which it is associated was conducted [17]. Factor structure was assessed with principal component analysis and a subsequent confirmatory factor analysis. A varimax rotation with Kaiser normalization was used in the total sample $(\mathrm{N}=323)$ at baseline to evaluate the principal components or factors. It was considered a Kaiser-Meyer-Olkin (KMO) $>0.80$ optimal and $<0.5$ insufficient [16]. The Bartlett test of sphericity was calculated to ascertain the correlations between the variables and the appropriateness of the factor model.

The convergent construct validity is the extent to which scores demonstrate expected logical relations with other variables. It was measured with the FSFI domain intercorrelations and the correlations between each domain and total score. While using the Pearson correlation, a value of $<0.3$ was considered to indicate a weak correlation, one of 0.3 to 0.5 a moderate correlation, and one of $>0.5$ a strong correlation [30].

The discriminant construct validity was calculated with an independent Student's T-test while comparing the difference of the scores of FSFI domains between case and control group.

The responsiveness or sensitivity to change was assessed in a subgroup of women with FSD who carried out a Physiotherapy treatment for pelvic floor during eight weeks. These women filled in the FSFI twice: at baseline, and after the Physiotherapy intervention. Three distribution-based methods were used in order to evaluate responsiveness: the $p$ values generated using the Wilcoxon signed-rank test, the effect size (ES), and the standardized response means for the change (SRM) in scores from pre- and post-Physiotherapy intervention using the paired $t$ test. For SRM and ES, a value of $0.2-0.5$ was considered as small, of $0.5-0.8$ as moderate, of above $0.8-1.0$ as good, and of more than 1.0 , excellent [31-33].

The percentage of unanswered individual items and the percentage of women who did not answer any of the items were analyzed to evaluate FSFI's Spanish version feasibility. Additionally, the average administration time was calculated. 


\section{Results}

\subsection{Study Participants Characteristics}

Three hundred and twenty-three consecutive women were recruited from March 2014 to May 2018; the sample characteristics are presented in Table 1. The sample women were categorized into the FSD group (167 (51.7\%)) and control group (156 (48.3\%)) according to the DSM-5 criteria.

Table 1. Baseline characteristics of participants.

\begin{tabular}{|c|c|c|}
\hline & $\begin{array}{l}\text { FSD Group } \\
(\mathrm{N}=167)\end{array}$ & $\begin{array}{l}\text { Control Group } \\
(\mathrm{N}=156)\end{array}$ \\
\hline Age (years, X (SD)) & $48(8)$ & $40(11)$ \\
\hline \multicolumn{3}{|l|}{ Education level $(n(\%))$} \\
\hline Primary School & $43(25.7 \%)$ & $22(14.1 \%)$ \\
\hline High School & $45(26.9 \%)$ & $40(25.6 \%)$ \\
\hline College or University & $79(47.3 \%)$ & $94(60.2 \%)$ \\
\hline \multicolumn{3}{|l|}{ Marital Status $(n(\%))$} \\
\hline Married & $116(69.4 \%)$ & $86(55.1 \%)$ \\
\hline In couple & $48(28.7 \%)$ & $57(36.5 \%)$ \\
\hline Single & $3(1.7 \%)$ & $13(8.3 \%)$ \\
\hline \multicolumn{3}{|l|}{ Occupational status $(n(\%))$} \\
\hline Housewife & $30(17.9 \%)$ & $13(8.3 \%)$ \\
\hline Employee & $123(73.6 \%)$ & $120(76.9 \%)$ \\
\hline Unemployed & $11(6.5 \%)$ & $7(4.4 \%)$ \\
\hline Student & $3(1.7 \%)$ & $16(10.2 \%)$ \\
\hline \multicolumn{3}{|c|}{ Annual family income $(€)(n(\%))$} \\
\hline$<12.000 €$ & $16(9.5 \%)$ & $11(7 \%)$ \\
\hline $12.000-24.000 €$ & $35(20.9 \%)$ & $34(21.7 \%)$ \\
\hline$>24.000-36.000 €$ & $57(34.1 \%)$ & $44(28.2 \%)$ \\
\hline$>36.000-48.000 €$ & $16(9.5 \%)$ & $23(14.7 \%)$ \\
\hline$>48.000 €$ & $14(8.3 \%)$ & $3(1.7 \%)$ \\
\hline Prefer don't say it & $29(17.4 \%)$ & $40(25.6 \%)$ \\
\hline \multicolumn{3}{|l|}{ Vaginal delivery $(n(\%))$} \\
\hline Nulliparous & $41(24.5 \%)$ & $62(39.7 \%)$ \\
\hline 1 & $57(34.1 \%)$ & $46(29.4 \%)$ \\
\hline 2 & $58(34.7 \%)$ & $35(22.4 \%)$ \\
\hline 3 & $6(3.5 \%)$ & $12(7.6 \%)$ \\
\hline 4 or more & $5(2.9 \%)$ & $1(0.6 \%)$ \\
\hline \multicolumn{3}{|l|}{ Menopause (n (\%)) } \\
\hline Yes & $58(34.7 \%)$ & $35(22.4 \%)$ \\
\hline No & $109(65.2 \%)$ & $121(77.6 \%)$ \\
\hline
\end{tabular}

$X(\mathrm{SD})$ : Mean (Standard Deviation); FSD: Female Sexual Dysfunction.

\subsection{Cultural Adaptation}

The cross-cultural adaptation of FSFI' Spanish version achieved a good semantic, conceptual, idiomatic, and content equivalences.

In the pilot study, most of the items were well understood. During the translation process and cognitive interviews, some words were identified and discussed until the most appropriate wording was found, i.e., "vaginal intercourse", "sexual intercourse", "intercourse", and "vaginal penetration" were translated like "coito vaginal". After having been revised by the expert panel, the Spanish final 
version was obtained (Table S2 Supplementary Material). This Spanish final version contained 19 questionnaire items that were divided into six dimensions, with a comparable structure to the original English version.

\subsection{Reliability}

31 women (16 from FSD group and 15 from control group) completed the FSFI questionnaire twice within 2-4 weeks from the basal visit in order to evaluate the test-retest reliability. The test-retest reliability showed high in all the cases, with ICC from 0.90 (95\% CI: 0.792-0.959) to 0.94 (95\% CI: 0.872-0.975) in the dimensions and with 0.96 (95\% CI: 0.910-0.982) in the total score (Table 2).

Table 2. Test-retest reliability for dimensions and total Female Sexual Function Index (FSFI) $(\mathrm{N}=31)$.

\begin{tabular}{ccc}
\hline & ICC & $\mathbf{9 5 \% ~ C I ~}$ \\
\hline Desire & 0.943 & $0.872-0.975$ \\
Arousal & 0.907 & $0.792-0.959$ \\
Lubrication & 0.939 & $0.864-0.973$ \\
Orgasm & 0.916 & $0.811-0.963$ \\
Satisfaction & 0.931 & $0.845-0.969$ \\
Pain & 0.930 & $0.844-0.969$ \\
Total FSFI & 0.960 & $0.910-0.982$ \\
\hline
\end{tabular}

In terms of internal consistency, FSFI showed high Cronbach's $\alpha$ coefficient values in all dimensions for all groups, both in the different dimensions the total score (Table 3).

Table 3. Internal consistency reliability for dimensions and total FSFI (Cronbach's Alpha).

\begin{tabular}{cccc}
\hline & $\begin{array}{c}\text { FSD Group } \\
(\mathbf{N}=\mathbf{1 6 7})\end{array}$ & $\begin{array}{c}\text { Control Group } \\
\mathbf{( N = 1 5 6 )}\end{array}$ & $\begin{array}{c}\text { Total Group } \\
\mathbf{( N = 3 2 3 )}\end{array}$ \\
\hline Desire & 0.752 & 0.749 & 0.760 \\
Arousal & 0.723 & 0.749 & 0.745 \\
Lubrication & 0.739 & 0.763 & 0.756 \\
Orgasm & 0.741 & 0.747 & 0.753 \\
Satisfaction & 0.739 & 0.739 & 0.753 \\
Pain & 0.753 & 0.762 & 0.765 \\
Total FSFI & 0.793 & 0.837 & 0.850 \\
\hline
\end{tabular}

FSD: Female Sexual Dysfunction.

\subsection{Validity}

In the pilot study, the revisions of women and Expert Committee' guaranteed adequate content validity of the Spanish version of FSFI, enough to evaluate the female sexual function.

Regarding the factor structure of the Spanish FSFI, a value of 0.861 was obtained in the Kaiser-Meyer-Olkin, with a Bartlett sphericity test. First, we used a minimum eigenvalue of 1.0 as a criterion factor extraction, and then four factors were identified with minimum eigenvalue of 1.30 and a total of $73.94 \%$ of the variance: desire/arousal, lubrication, orgasm/satisfaction, and pain. A second principal component analysis was calculated based in the studies of the original FSFI and of the FSFI confirmatory factor analysis [34] that decided a six-factor structure. In this way, the six-factor solution accounted a total of $82.57 \%$ of the variance and the lowest eigenvalue was 0.76 , including the domains of: desire, arousal, lubrication, orgasm, satisfaction, and pain (Table 4). In this six-factor analysis, the minimum factor loading was 0.633 . 
Table 4. Factor analysis of the FSFI: factorial validity $(\mathrm{N}=323)$.

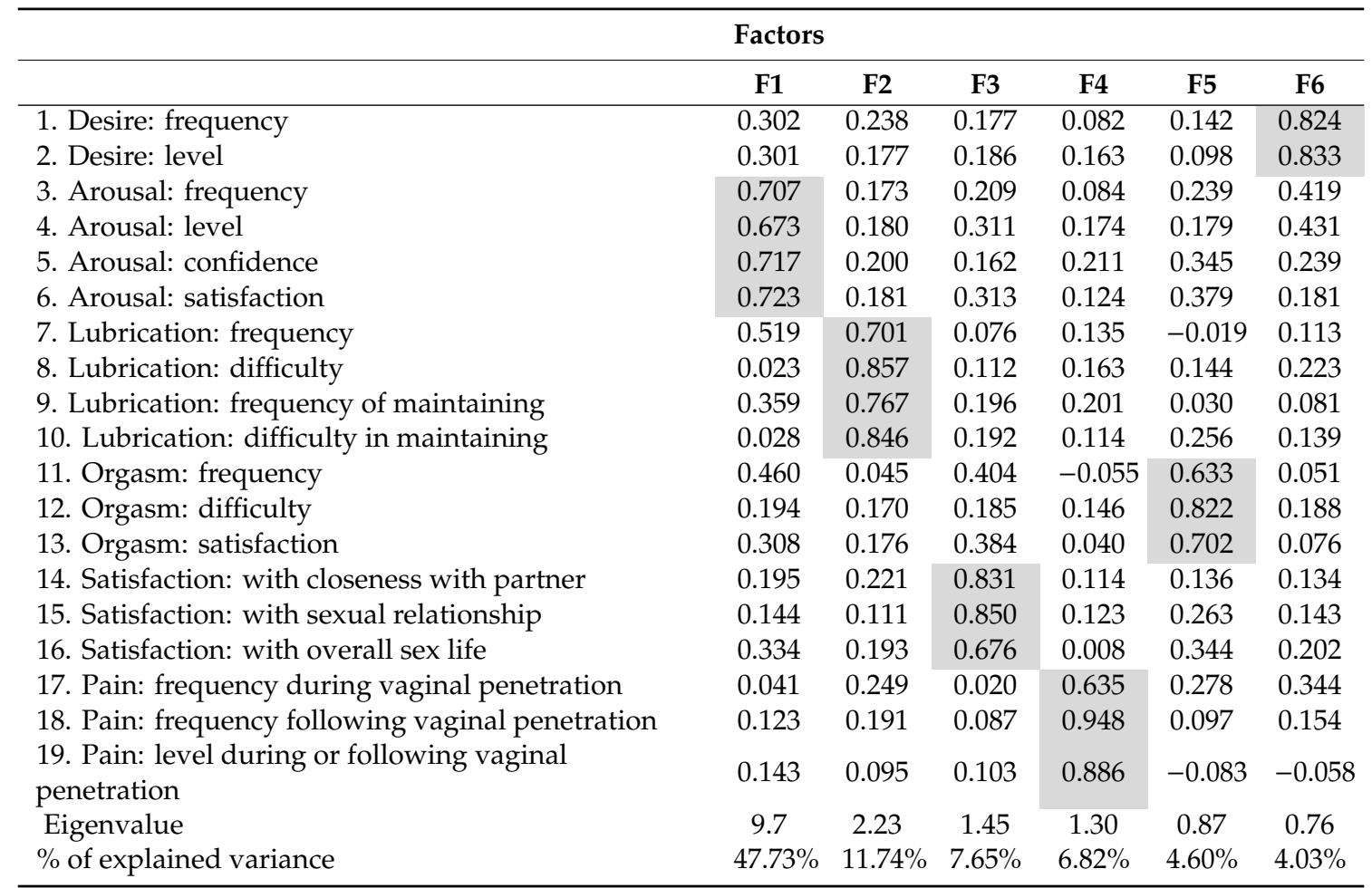

Principal component analysis using rotation method varimax with Kaiser normalization. Items with the highest factor loading in each principal component are shaded. F1: Arousal, F2: Lubrication, F3: Satisfaction, F4: Pain, F5: Orgasm, F6: Desire.

Convergent construct validity, calculated with the domain intercorrelations and correlations between each domain and total FSFI, using Pearson's, showed high in all of the groups and observed higher values in the total group. The values were higher in the correlation of total FSFI and domains than in interdomains. The domains that showed higher intercorrelations were observed for arousal with desire, orgasm, and satisfaction; and, orgasm with satisfaction (Table 5).

Table 5. FSFI Domains intercorrelations (Pearson r).

\begin{tabular}{|c|c|c|c|c|c|c|c|}
\hline TOTAL GROUP & Desire & Arousal & Lubrication & Orgasm & Satisfaction & Pain & Total FSFI \\
\hline Desire & 1 & & & & & & \\
\hline Arousal & $0.676\left(^{* *}\right)$ & 1 & & & & & \\
\hline Lubrication & $\left.0.455^{* *}\right)$ & $0.560\left(^{* *}\right)$ & 1 & & & & \\
\hline Orgasm & $\left.0.439{ }^{* *}\right)$ & $\left.0.6855^{* *}\right)$ & $0.427\left(^{* *}\right)$ & 1 & & & \\
\hline Satisfaction & $\left.0.4644^{* *}\right)$ & $0.632\left(^{* *}\right)$ & $\left.0.4677^{* *}\right)$ & $\left.0.6944^{* *}\right)$ & 1 & & \\
\hline Pain & $\left.0.3511^{* *}\right)$ & $\left.0.381^{* *}\right)$ & $\left.0.4622^{* *}\right)$ & $\left.0.3322^{* *}\right)$ & $\left.0.3633^{* *}\right)$ & 1 & \\
\hline Total FSFI & $\left.0.730{ }^{* *}\right)$ & $0.853(* *)$ & $0.742(* *)$ & $\left.0.780{ }^{* *}\right)$ & $0.792(* *)$ & $0.653(* *)$ & 1 \\
\hline FSD GROUP & Desire & Arousal & Lubrication & Orgasm & Satisfaction & Pain & Total FSFI \\
\hline Desire & 1 & & & & & & \\
\hline Arousal & $\left.0.614{ }^{* *}\right)$ & 1 & & & & & \\
\hline Lubrication & $0.364\left(^{* *}\right)$ & $0.494\left(^{* *}\right)$ & 1 & & & & \\
\hline Orgasm & $\left.0.275{ }^{* *}\right)$ & $0.638\left(^{* *}\right)$ & $0.307\left(^{* *}\right)$ & 1 & & & \\
\hline Satisfaction & $\left.0.370^{* *}\right)$ & $0.619\left(^{* *}\right)$ & $0.352(* *)$ & $\left.0.656{ }^{* *}\right)$ & 1 & & \\
\hline Pain & $\left.0.210^{* *}\right)$ & $\left.0.273^{* *}\right)$ & $\left.0.439{ }^{* *}\right)$ & $0.180\left(^{*}\right)$ & $0.214(* *)$ & 1 & \\
\hline Total FSFI & $\left.0.640{ }^{* *}\right)$ & $\left.0.8399^{* *}\right)$ & $\left.0.705{ }^{* *}\right)$ & $0.712\left(^{* *}\right)$ & $0.744(* *)$ & $\left.0.591{ }^{* *}\right)$ & 1 \\
\hline
\end{tabular}


Table 5. Cont.

\begin{tabular}{|c|c|c|c|c|c|c|c|}
\hline CONTROL GROUP & Desire & Arousal & Lubrication & Orgasm & Satisfaction & Pain & Total FSFI \\
\hline Desire & 1 & & & & & & \\
\hline Arousal & $\left.0.644{ }^{* *}\right)$ & 1 & & & & & \\
\hline Lubrication & $\left.0.3588^{* *}\right)$ & $\left.0.459{ }^{(* *}\right)$ & 1 & & & & \\
\hline Orgasm & $0.466(* *)$ & $0.616\left(^{* *}\right)$ & $\left.0.3899^{* *}\right)$ & 1 & & & \\
\hline Satisfaction & $0.419^{(* *)}$ & $0.519\left(^{* *}\right)$ & $0.498\left(^{* *}\right)$ & $0.655\left(^{* *}\right)$ & 1 & & \\
\hline Pain & $\left.0.386{ }^{* *}\right)$ & $\left.0.376^{(* *}\right)$ & $\left.0.259{ }^{* *}\right)$ & $0.418\left(^{* *}\right)$ & $0.483(* *)$ & 1 & \\
\hline Total FSFI & $\left.0.731{ }^{* *}\right)$ & $\left.0.798{ }^{* *}\right)$ & $0.657\left(^{(* *}\right)$ & $0.792(* *)$ & $0.814(* *)$ & $0.650\left(^{* *}\right)$ & 1 \\
\hline
\end{tabular}

About the discriminant construct validity, the scores for each FSFI domains and total FSFI showed statistically significant differences between the FSD group and the control group $(p<0.05)$ (Table 6$)$. The difference between the total scale score was 5.128 (95\% CI: 4.087-6.170).

Table 6. Discriminant construct validity: correlation of FSFI domains scores between cases and control group (Paired $t$-test).

\begin{tabular}{|c|c|c|c|c|c|c|}
\hline & $\begin{array}{c}\text { FSD } \\
\text { Group } \\
(\mathrm{N}=167) \\
X(\mathrm{SD})\end{array}$ & $\begin{array}{c}\text { Control } \\
\text { Group } \\
(\mathrm{N}=156) \\
X \text { (SD) }\end{array}$ & $\begin{array}{c}\text { Mean } \\
\text { Difference }\end{array}$ & $95 \%$ CI & T Value & $p$ Value \\
\hline Desire & $3.3(1.12)$ & $4.2(0.95)$ & 0.899 & $0.672-1.126$ & 7.797 & $<0.001$ \\
\hline Arousal & $4.2(1.26)$ & $5.1(0.80)$ & 0.890 & 0.661-1.119 & 7.642 & $<0.001$ \\
\hline Lubrication & 4.5 (1.33) & $5.4(0.82)$ & 0.925 & $0.685-1.166$ & 7.566 & $<0.001$ \\
\hline Orgasm & $4.4(1.26)$ & $5.3(0.85)$ & 0.891 & $0.657-1.125$ & 7.499 & $<0.001$ \\
\hline Satisfaction & $4.5(1.18)$ & $5.2(0.95)$ & 0.721 & $0.487-0.955$ & 6.063 & $<0.001$ \\
\hline Pain & $4.8(1.48)$ & $5.6(0.88)$ & 0.792 & $0.527-1.057$ & 5.880 & $<0.001$ \\
\hline Total FSFI & $25.7(5.49)$ & 30.9 (3.99) & 5.128 & $4.087-6.170$ & 9.691 & $<0.001$ \\
\hline
\end{tabular}

$p<0.05$ is considered statistically significant. X (SD): Mean (Standard Deviation); FSD: Female Sexual Dysfunction. CI: confidence interval.

\subsection{Responsiveness}

To assess responsiveness, a total of 92 women were recruited from the FSD group. Table 7 presents the baseline characteristics of these women. About the ES and SRM, they showed moderate to good in the FSFI dimensions, the lowest value being in the desire dimension (ES 0.69 and SRM $0.58 ; p<0.001$ ) and the highest in the pain dimension (ES 1.05 and SRM 1.01; $p<0.001$ ). Regarding the ES and SRM of the total FSFI, both of the values showed excellent responsiveness (ES 1.24 and SRM 1.11; $p<0.001$ ) (Table 8).

Table 7. Baseline characteristics of women for responsiveness $(\mathrm{N}=92)$.

\begin{tabular}{lc}
\hline Age (years, $X(\mathrm{SD}))$ & $50(6)$ \\
\hline Education level $(n(\%))$ & \\
\hline Primary School & $10(10.8 \%)$ \\
High School & $24(26.0 \%)$ \\
College or University & $58(63.0 \%)$ \\
\hline Marital Status $(n(\%))$ & \\
\hline Married & $49(53.3 \%)$ \\
In couple & $43(46.7 \%)$ \\
Single & - \\
\hline
\end{tabular}


Table 7. Cont.

\begin{tabular}{cc}
\hline Occupational status $(n(\%))$ & \\
\hline Housewife & $11(11.9 \%)$ \\
Employee & $76(82.6 \%)$ \\
Unemployed & $5(5.4 \%)$ \\
Student & - \\
\hline Annual family income $(€)(n(\%))$ & \\
\hline$<12.000 €$ & $4(4.3 \%)$ \\
$12.000-24.000 €$ & $29(31.5 \%)$ \\
$>24.000-36.000 €$ & $34(36.9 \%)$ \\
$>36.000-48.000 €$ & $15(16.3 \%)$ \\
$>48.000 €$ & $4(4.3 \%)$ \\
Prefer don't say it & $6(6.5 \%)$ \\
\hline Vaginal delivery $(n(\%))$ & \\
\hline Nulliparous & $2(2.2 \%)$ \\
1 & $63(68.5 \%)$ \\
2 & $27(29.3 \%)$ \\
3 & - \\
4 or more & - \\
\hline Menopause $(n(\%))$ & \\
\hline Yes & $33(64.1 \%)$ \\
No & $59(35.9 \%)$ \\
\hline
\end{tabular}

$X$ (SD): Mean (Standard Deviation); FSD: Female Sexual Dysfunction.

Table 8. FSFI Mean change in scores, and responsiveness.

\begin{tabular}{cccccccc}
\hline N = 92 & $\begin{array}{c}\text { Pretreatment } \\
\boldsymbol{X} \text { (SD) Score }\end{array}$ & $\begin{array}{c}\text { Posttreatment } \\
\boldsymbol{X} \text { (SD) Score }\end{array}$ & $\begin{array}{c}\text { Mean Change } \\
\text { in Score (SD) }\end{array}$ & $\mathbf{9 5 \% \text { CI }}$ & T Value & $\begin{array}{c}p \text { Value } \\
\begin{array}{c}\text { Effect } \\
\text { Size (ES) }\end{array}\end{array} \begin{array}{c}\text { Standardized } \\
\text { Response } \\
\text { Mean (SRM) }\end{array}$ \\
\hline Desire & $3.1(1.01)$ & $3.8(0.99)$ & $0.7(1.21)$ & $0.492-0.995$ & 5.873 & $<0.001$ & 0.69 \\
Arousal & $3.4(1.31)$ & $4.7(1.09)$ & $1.3(1.58)$ & $0.977-1.631$ & 7.914 & $<0.001$ & 0.99 \\
Lubrication & $3.4(1.63)$ & $4.9(1.25)$ & $1.5(1.76)$ & $1.149-1.882$ & 8.221 & $<0.001$ & 0.92 \\
Orgasm & $3.5(1.65)$ & $5.0(1.17)$ & $1.5(1.79)$ & $1.197-1.941$ & 8.378 & $<0.001$ & 0.91 \\
Satisfaction & $3.8(1.33)$ & $5.0(1.02)$ & $1.2(1.46)$ & $0.952-1.560$ & 8.212 & $<0.001$ & 0.90 \\
Pain & $3.4(1.81)$ & $5.3(1.01)$ & $1.9(1.89)$ & $1.550-2.336$ & 9.821 & $<0.001$ & 1.05 \\
Total FSFI & $20.7(6.71)$ & $29.0(5.26)$ & $8.3(7.45)$ & $6.788-9.878$ & 10.715 & $<0.001$ & 1.24 \\
\hline
\end{tabular}

$p<0.05$ is considered statistically significant. $X(\mathrm{SD})$ : Mean (Standard Deviation); SD: standard deviation; ES effect size; SRM: standardized response means. CI: confidence interval.

\subsection{Feasibility}

Concerning feasibility, the average time for questionnaire administration was 4.33 (1.74) min. for the FSFI's Spanish version. All of the FSFI questionnaires were self-reported by the women in the consult. Accordingly, the women with non-response item were zero in the six dimensions, and the majority of items were easily understood.

\section{Discussion}

PFD have been shown to have a significant impact on quality of life, which includes the sexual function. The FSFI is regarded as the gold standard to evaluate female sexual function [22]. It was developed and validated in English language and it has been adapted and validated to numerous languages, which allows for the possibility of international multicenter studies and comparing results of studies from different countries. In this way, the Chilean and Colombian FSFI $[23,24]$ must not be used in Spanish women from Spain, because they have been cross-cultural adapted and validated in a different sociocultural environment. In fact, some of the authors have proposed Guidelines in order to adapt questionnaires into the same language within different cultures [35,36], so it has been 
recognized that culture affects sexual function [37], and it is usually modulated by moral, religious, or ethical criteria, so the results of research in a country may not be applicable in another. Secondly, it is essential to assess the psychometric properties of the validated tool to the target population, in our case, Spanish women. Therefore, using a validated tool for Iberoamerican countries in a Spanish population might be a significant source of bias in the obtained data.

The method used in the present study for the FSFI's Spanish version is similar to that performed in the others FSFI's validity versions, including a first stage of translation of original English FSFI to Spanish FSFI questionnaire and another to evaluate the psychometric properties in a female sample.

As we know, this study is the first FSFI validity study that evaluates responsiveness. It is widely argued that outcome measures in clinical trials should show not only validity and reliability, but also responsiveness or sensitiveness to change [38]. Responsiveness is the ability to detect changes that occur as a result of therapy or disease progression and it has been suggested as one criterion to choose among the scales used to evaluate the efficacy of a therapeutic intervention. In fact, a low response can produce the lack of difference when a real difference, in fact, exists (risk of a type II error), which can lead to an underestimation on the effect of treatment [39]. Hence, we consider responsiveness to be a fundamental psychometric characteristic that should be assessed in our study. Regarding the female sample, we have included women with PFD, which differs from women included in others FSFI validations. Sociodemographic characteristics showed that the age of sample was similar to the original and validations FSFI studies, in our study of 48 [8] in the FSD group and of 40 [11] in the control group. In the Spanish validation, like in the rest of them, the age of the FSD group was higher than that of the control group; in fact, the age has been identified as a significant factor that is predictive of the worsening of the sexual function [11].

The results concerning reliability, internal consistency, and test-retest reproducibility showed high. Cronbach's Alpha showed similar in all the groups, with good values in all of the cases. The test-retest reliability demonstrated significant correlations two to four weeks, with Pearson correlation coefficient of, at least, 0.90 .

Convergent construct validity showed that all of the domains were correlated in the total group. The highest correlations were found between arousal with desire, orgasm, and satisfaction and between orgasm with satisfaction. These results can be also observed in the original study. The domains correlations were higher for the total group, it was also found in the original and Malay versions $[17,40]$.

In the present study, analysis of discriminant validity has been measured calculating the difference between the FSD and control group. This method has also been adopted in others validations, like original, the Chinese, the Iranian, and the Malay $[16,17,19,40]$, and, as in these studies, our results showed that the scores for each domains and full-scale of FSFI are significantly higher for the FSD group as compared to control group.

Regarding the principal component analysis in the present study, like in the Chinese validation, a first principal component analysis identified four factors, but eventually six factors were identified based in the FSFI original structure and in the FSFI confirmatory factor analysis study. The first four-factor solution accounted the $73.94 \%$ of the explained variance, with a lowest eigenvalue of 1.30 and including the domains of desire/arousal, lubrication, orgasm/satisfaction, and pain. In other way, the six-factor solution every extracted factor had a reasonable and clear explanation that accounted for the $82.57 \%$ of the explained variance and showed high-factor loading for the six identified dimensions: desire, arousal, lubrication, orgasm, satisfaction, and pain, with a minimum loading of 0.633 and a maximum loading of 0.948 , showed a reasonable and clear explanation of the extracted factor and therefore, the factorial validity of the Spanish FSFI. Previous FSFI validations showed inconsistent findings regarding factor solution, identifying from three (Taiwan version [41]) to six factors, although most studies have finally showed six factors, like the original study did (Chinese, Arabic, and Colombian versions).

As a limitation in this study, we find that the sample are women with PFD, which could influence in the female sexual health and, so, it could affect the obtained data. This fact might involve a limitation 
in the generalizability of the application of FSFI to the general Spanish women population. In this way, future validation in diverse subpopulation are recommended.

\section{Conclusions}

The Spanish FSFI can be used as a reliable, valid, responsive, and feasible instrument for assessing sexual function in Spanish women with PFD.

Supplementary Materials: The following are available online at http://www.mdpi.com/1660-4601/17/3/994/s1, Table S1: STROBE Statement, Table S2: Spanish FSFI (Índice de la Función Sexual Femenina) and scoring.

Author Contributions: Conceptualization, B.S.-S. and M.T.-L.; Methodology, B.S.-S. and M.T.-L.; Validation, B.S.-S., B.N.-B. and M.T.-L.; Formal Analysis, Ó.S.-M.; Investigation, B.S.-S., B.A.-M. and M.T.-L.; Data Curation, B.A.-M. and I.d.l.R.-D.; Resources, M.T.-L.; Writing-Original Draft Preparation, B.S.-S.; Writing-Review \& Editing, B.S.-S., M.T.-L., I.d.l.R.-D. and Ó.S.-M.; Visualization, B.N.-B.; Supervision, M.T.-L. All authors have read and agreed to the published version of the manuscript.

Funding: This research received no external funding.

Acknowledgments: We thank to the women who participated in this study and to Carlos Gutiérrez-Ortega for his always valuable statistical support.

Conflicts of Interest: The authors declare no conflict of interest.

\section{References}

1. World Health Organization. Defining Sexual Health: Report of a Technical Consultation on Sexual Health; World Health Organization: Geneva, Switzerland, 2002.

2. Rosen, R.C.; Taylor, J.F.; Leiblum, S.R.; Bachmann, G.A. Prevalence of sexual dysfunction in women: Results of a survey study of 329 women in an outpatient gynecological clinic. J. Sex. Marital Ther. 1993, 19, 171-188. [CrossRef]

3. McCabe, M.P.; Sharlip, I.D.; Lewis, R.; Atalla, E.; Balon, R.; Fisher, A.D.; Laumann, E.; Lee, S.W.; Segraves, R.T. Incidence and prevalence of sexual dysfunction in women and men: A consensus statement from the Fourth International Consultation on Sexual Medicine 2015. J. Sex. Med. 2016, 13, 144-152. [CrossRef] [PubMed]

4. McCabe, M.P.; Sharlip, I.D.; Lewis, R.; Atalla, E.; Balon, R.; Fisher, A.D.; Laumann, E.; Lee, S.W.; Segraves, R.T. Definitions of sexual dysfunctions in women and men: A consensus statement from the Fourth International Consultation on Sexual Medicine 2015. J. Sex. Med. 2016, 13, 135-143. [CrossRef]

5. Maiorino, M.I.; Bellastella, G.; Giugliano, D.; Esposito, K. From inflammation to sexual dysfunctions: A journey through diabetes, obesity, and metabolic syndrome. J. Endocrinol. Investig. 2018, 41, 1249-1258. [CrossRef]

6. Achtari, C.; Dwyer, P.L. Sexual function and pelvic floor disorders. Best Pract. Res. Clin. Obstet. Gynaecol. 2005, 19, 993-1008. [CrossRef]

7. Laumann, E.O.; Paik, A.; Rosen, R.C. Sexual dysfunction in the United States: Prevalence and predictors. JAMA 1999, 281, 537-544. [CrossRef]

8. Bortolami, A.; Vanti, C.; Banchelli, F.; Guccione, A.A.; Pillastrini, P. Relationship between female pelvic floor dysfunction and sexual dysfunction: An observational study. J. Sex. Med. 2015, 12, 1233-1241. [CrossRef]

9. Handa, V.L.; Harvey, L.; Cundiff, G.W.; Siddique, S.A.; Kjerulff, K.H. Sexual function among women with urinary incontinence and pelvic organ prolapse. Obstet. Gynecol. 2004, 191, 751-756. [CrossRef]

10. Barber, M.D.; Visco, A.G.; Wyman, J.F.; Fantl, J.A.; Bump, R.C. Continence Program for Women Research Group. Sexual function in women with urinary incontinence and pelvic organ prolapse. Obstet. Gynecol. 2002, 99, 281-289. [PubMed]

11. Lukacz, E.S.; Whitcomb, E.L.; Lawrence, J.M.; Nager, C.W.; Contreras, R.; Luber, K.M. Are sexual activity and satisfaction affected by pelvic floor disorders? Analysis of a community-Based survey. Obstet. Gynecol. 2007, 197, 88. [CrossRef] [PubMed]

12. Balzarro, M.; Rubilotta, E.; Mancini, V.; Trabacchin, N.; Oppezzi, L.; Li Marzi, V.; Fusco, F.; Serati, M. Impact of Overactive Bladder-Wet Syndrome on Female Sexual Function: A Systematic Review and Meta-Analysis. Sex. Med. Rev. 2019, 7, 565-574. [CrossRef] [PubMed] 
13. Handa, V.L.; Cundiff, G.; Chang, H.H.; Helzlsouer, K.J. Female sexual function and pelvic floor disorders. Obstet. Gynecol. 2008, 111, 1045. [CrossRef] [PubMed]

14. Barber, M.D.; Walters, M.D.; Bump, R.C. Short forms of two condition-Specific quality-Of-Life questionnaires for women with pelvic floor disorders (PFDI-20 and PFIQ-7). Obstet. Gynecol. 2005, 193, 103-113. [CrossRef] [PubMed]

15. Sánchez-Sánchez, B.; Torres-Lacomba, M.; Yuste-Sánchez, M.J.; Navarro-Brazález, B.; Pacheco-da-Costa, S.; Gutiérrez-Ortega, C. Cultural adaptation and validation of the pelvic floor distress inventory short form (PFDI-20) and pelvic floor impact questionnaire short form (PFIQ-7) Spanish versions. Eur. J. Obstet. Gynecol. Reprod. Biol. 2013, 170, 281-285. [CrossRef]

16. Fakhri, A.; Pakpour, A.H.; Burri, A.; Morshedi, H.; Zeidi, I.M. The Female Sexual Function Index: Translation and validation of an Iranian version. J. Sex. Med. 2012, 9, 514-523. [CrossRef]

17. Rosen, C.; Brown, J.; Heiman, S.; Leiblum, C.; Meston, R.; Shabsigh, D.; Ferguson, R.; D'Agostino, R. The Female Sexual Function Index (FSFI): A multidimensional self-Report instrument for the assessment of female sexual function. J. Sex. Marital Ther. 2000, 26, 191-208. [CrossRef]

18. Ryding, E.L.; Blom, C. Validation of the Swedish version of the Female Sexual Function Index (FSFI) in women with hypoactive sexual desire disorder. J. Sex. Med. 2015, 12, 341-349. [CrossRef]

19. Sun, X.; Li, C.; Jin, L.; Fan, Y.; Wang, D. Development and validation of Chinese version of Female Sexual Function Index in a Chinese population-A pilot study. J. Sex. Med. 2011, 8, 1101-1111. [CrossRef]

20. Takahashi, M.; Inokuchi, T.; Watanabe, C.; Saito, T.; Kai, I. The Female Sexual Function Index (FSFI): Development of a Japanese Version. J. Sex. Med. 2011, 8, 2246-2254. [CrossRef]

21. Anis, T.H.; Gheit, S.A.; Saied, H.S.; Al_kherbash, S.A. Arabic translation of Female Sexual Function Index and validation in an Egyptian population. J. Sex. Med. 2011, 8, 3370-3378. [CrossRef]

22. Sand, M.; Rosen, R.; Meston, C.; Brotto, L.A. The female sexual function index (FSFI): A potential "gold standard" measure for assessing therapeutically-Induced change in female sexual function. Fertil. Steril. 2009, 92, S129. [CrossRef]

23. Blümel, J.E.; Binfa, L.; Cataldo, P.; Carrasco, A.; Izaguirre, H.; Sarr, S. Índice de función sexual femenina: Un test para evaluar la sexualidad de la mujer. Revista Chilena de Obstetricia y Ginecologa 2004, 69, 118-125. [CrossRef]

24. Vallejo-Medina, P.; Prez-Durn, C.; Saavedra-Roa, A. Translation, Adaptation, and Preliminary Validation of the Female Sexual Function Index into Spanish (Colombia). Arch. Sex. Behav. 2017, 47, 797-810. [CrossRef] [PubMed]

25. Wild, D.; Grove, A.; Martin, M.; Eremenco, S.; McElroy, S.; Verjee-Lorenz, A.; Erikson, P. Principles of good practice for the translation and cultural adaptation process for patient-Reported outcomes (PRO) measures: Report of the ISPOR task force for translation and cultural adaptation. Value Health 2005, 8, 94-104. [CrossRef]

26. DSM-5 American Psychiatric Association. Diagnostic and Statistical Manual of Mental Disorders; American Psychiatric Publishing: Washington, DC, USA, 2013.

27. Terwee, C.B.; Bot, S.D.; de Boer, M.R.; van der Windt, D.A.; Danille, A.W.M.; Knol, D.L.; Dekker, J.; Bouter, L.M.; de Vet, H.C. Quality criteria were proposed for measurement properties of health status questionnaires. J. Clin. Epidemiol. 2007, 60, 34-42. [CrossRef]

28. Mokkink, L.B.; Terwee, C.B.; Patrick, D.L.; Alonso, J.; Stratford, P.W.; Knol, D.L.; Bouter, L.M.; de Vet, H.C. The COSMIN study reached international consensus on taxonomy, terminology, and definitions of measurement properties for health-Related patient-Reported outcomes. J. Clin. Epidemiol. 2010, 63, 737-745. [CrossRef]

29. Rothman, M.; Burke, L.; Erickson, P.; Leidy, N.K.; Patrick, D.L.; Petrie, C.D. Use of existing patient-Reported outcome (PRO) instruments and their modification: The ISPOR Good Research Practices for Evaluating and Documenting Content Validity for the Use of Existing Instruments and Their Modification PRO Task Force Report. Value Health 2009, 12, 1075-1083. [CrossRef]

30. Cohen, J. Statistical Power Analysis for the Behavioral Sciences, 2nd ed.; Lawrence Erlbaum Associates: New York, NY, USA, 1988.

31. Crosby, R.D.; Kolotkin, R.L.; Williams, G.R. Defining clinically meaningful change in health-Related quality of life. J. Clin. Epidemiol. 2003, 56, 395-407. [CrossRef]

32. Terwee, C.; Dekker, F.; Wiersinga, W.; Prummel, M.; Bossuyt, P. On assessing responsiveness of health-Related quality of life instruments: Guidelines for instrument evaluation. Qual. Life Res. 2003, 12, 349-362. [CrossRef] 
33. Sánchez, B.S.; Lacomba, M.T.; Brazález, B.N.; Téllez, E.C.; Da Costa, S.P.; Ortega, C.G. Responsiveness of the Spanish Pelvic Floor Distress Inventory and Pelvic Floor Impact Questionnaires Short Forms (PFDI-20 and PFIQ-7) in women with pelvic floor disorders. Eur. J. Obstet. Gynecol. Reprod. Biol. 2015, 190, $20-25$. [CrossRef]

34. Opperman, E.A.; Benson, L.E.; Milhausen, R.R. Confirmatory factor analysis of the Female Sexual Function Index. J. Sex. Res. 2013, 50, 29-36. [CrossRef] [PubMed]

35. Vallejo-Medina, P.; Gómez-Lugo, M.; Marchal-Bertrand, L.; Saavedra-Roa, A.; Soler, F.; Morales, A. Developing guidelines for adapting questionnaires into the same language in another culture. Terapia Psicológica 2017, 35, 159-172. [CrossRef]

36. Valderas, J.M.; Ferrer, M.; Alonso, J. Instrumentos de medida de calidad de vida relacionada con la salud y de otros resultados percibidos por los pacientes. Medicina Clínica 2005, 125, 56-60. [CrossRef]

37. Brotto, L.A.; Chik, H.M.; Ryder, A.G.; Gorzalka, B.B.; Seal, B.N. Acculturation and sexual function in Asian women. Arch. Sex. Behav. 2005, 34, 613-626. [CrossRef] [PubMed]

38. Husted, J.A.; Cook, R.J.; Farewell, V.T.; Gladman, D.D. Methods for assessing responsiveness: A critical review and recommendations. J. Clin. Epidemiol. 2000, 53, 459-468. [CrossRef]

39. Barber, M.D.; Walters, M.D.; Cundiff, G.W. Responsiveness of the Pelvic Floor Distress Inventory (PFDI) and Pelvic Floor Impact Questionnaire (PFIQ) in women undergoing vaginal surgery and pessary treatment for pelvic organ prolapse. Obstet. Gynecol. 2006, 194, 1492-1498. [CrossRef]

40. Sidi, H.; Abdullah, N.; Puteh, S.E.W.; Midin, M. The Female Sexual Function Index (FSFI): Validation of the Malay Version. J. Sex. Med. 2007, 4, 1642-1654. [CrossRef]

41. Chang, S.; Chang, T.; Chen, K.; Lin, H. Developing and Validating a Taiwan Version of the Female Sexual Function Index for Pregnant Women. J. Sex. Med. 2009, 6, 1609-1616. [CrossRef]

(C) 2020 by the authors. Licensee MDPI, Basel, Switzerland. This article is an open access article distributed under the terms and conditions of the Creative Commons Attribution (CC BY) license (http://creativecommons.org/licenses/by/4.0/). 